\title{
(2) OPEN ACCESS \\ Incubator traffic light: the development of an alcohol-based hand rub dispenser system for neonatal incubators with visual feedback to improve hand hygiene compliance
}

\author{
Ronald H J van Gils (D) ,', ${ }^{1,2}$ Onno K Helder, ${ }^{2,3,4}$ Linda S G L Wauben $^{2,5}$
}

For numbered affiliations see end of article.

\section{Correspondence to} Ronald H J van Gils, Institute of Engineering \& Applied Science, Rotterdam University of Applied Sciences, Postbus 25035, 3001HA Rotterdam, the Netherlands; r.h.j.van.gils@hr.nl

Received 12 June 2018 Revised 8 May 2019 Accepted 11 August 2019 Published Online First 6 September 2019
A) Check for updates

\section{(C) Author(s) (or their} employer(s)) 2019. Re-use permitted under CC BY-NC. No commercial re-use. See rights and permissions. Published by BMJ.

To cite: van Gils RHJ,

Helder OK, Wauben LSGL. BMJ Innov 2019;5:70-77.

\section{ABSTRACT}

Introduction Sustained high compliance with hand hygiene prior to patient contact in a neonatal intensive care unit (NICU) could reduce the spread of pathogens and incidence of bloodstream infections of preterm infants. These infections are associated with high mortality, morbidity and additional costs. Behaviour change interventions to promote hand hygiene, such as education, have only temporary beneficial effect on compliance. Our aim is to develop a technical intervention that supports a sustainable behaviour change for appropriate hand hygiene among NICU healthcare professionals.

Methods Students from different disciplines incrementally designed and evaluated solutions in co-creation with healthcare professionals of a NICU in a teaching hospital.

Results A prototype of the 'Incubator Traffic Light' system for neonatal incubators was developed, that is, a touchless alcohol-based hand rub (ABHR) dispenser with integrated colour display and incubator door sensor with lights. The system provides visual feedback to support healthcare professionals' compliance with the prescribed $30 \mathrm{~s}$ drying time for $A B H R$. After 30 s, green lights indicate that the incubator doors may be opened. In the event that doors are opened without dispensing $A B H R$ or earlier than 30 s, blinking orange lights and a display message urge the person to close the doors. The system documents compliance data in a web-based database.

Conclusions We developed a sophisticated technical intervention to support hand hygiene compliance. It is ready for clinical tests that should prove that the system contributes to sustainable hand hygiene compliance near neonatal incubators.

\section{INTRODUCTION}

Worldwide, $10 \%$ of infants are prematurely born $(<37$ weeks of gestational age). ${ }^{1}$ The most vulnerable of these are admitted to a neonatal intensive care unit (NICU). Infants with a very low birth weight $(<1500 \mathrm{~g})$ carry a high risk of bloodstream infection due to the immature host defence; incidences ranging from $11 \%$ to $53 \%$ have been reported. ${ }^{23}$ These children are placed in an incubator to keep their body temperature stable and to allow for optimal observation.

Bloodstream infections in preterm infants are associated with severe complications, such as severe cerebral haemorrhage, loss of hearing, spasticity, necrotising enterocolitis, chronic lung diseases, retinopathy and poor (neuro) developmental outcomes; they can even lead to lifelong disability and death. ${ }^{24-7}$ Affected infants stay some 12 days longer than the average duration, which incurs additional costs. ${ }^{8}$ Furthermore, these infections need to be treated with antibiotics, thus raising the risk of antibacterial resistance. $^{9}$

The WHO and the Centres for Disease Prevention and Control recommend correct hand hygiene as the best method to reduce the horizontal (patient to patient) 
spread of pathogens by healthcare professionals. ${ }^{10}$ Hand hygiene is a major element of many bundles of measures to prevent (bloodstream) infections. ${ }^{2} 1112$ Correct hand disinfection is achieved by rubbing the hands with a liberal amount of alcohol-based hand rub (ABHR) and let them dry for at least $30 \mathrm{~s}$ to kill off micro-organisms.

This procedure is in accordance with the European guideline $\mathrm{EN} 1500^{13}$ and the manufacturer userinstructions of the ABHR used at the NICU of this study (Manusept basic, Bode Chemie GmbH, Hamburg, Germany). Besides rubbing time other factors are relevant like the amount of applied ABHR and the rubbing technique (the way the ABHR is distributed over the hands and fingers).

Regrettably, hospital staff compliance with hand hygiene protocols is generally low. Studies found that only $20 \%-45 \%$ of staff disinfected their hands adequately by protocol; others simply forgot or felt work pressure. ${ }^{314-16}$

A variety of non-technical and technical (electronic) systems have been developed to monitor hand hygiene compliance, some of which also aim to improve compliance by behaviour change. ${ }^{1718}$ The use of advanced electronic systems that provide real-time individual feedback about hand hygiene compliance resulted in a short-term beneficial effect on compliance. ${ }^{18}$ None of the existent systems monitors compliance with the required (30s) drying time and is dedicated to hand hygiene practices near a neonatal incubator. ${ }^{19-21}$

Long-lasting high compliance with hand hygiene could perhaps be achieved with a closed-loop feedback system ${ }^{20} 22$ that provides visual feedback prompts when someone uses the ABHR dispenser and opens the incubator doors. We aimed to design an incubator hand hygiene feedback system that reminds users to wet and rub hands with ABHR and apply at least $30 \mathrm{~s}$ drying time, and also documents compliance and noncompliance in a web-based database.

\section{MATERIALS AND METHODS}

The feedback system was co-designed in an educational setting by researchers and students of the Rotterdam
University of Applied Sciences together with nurses, medical doctors, Newborn Individualised Developmental Care and Assessment Programme (NIDCAP) ${ }^{23}$ certified specialists, housekeeping staff, infection prevention specialists and medical device safety specialists of the NICU of the Erasmus MC-Sophia Children's Hospital, in incremental design-research projects between 2011 and 2016. A participatory design approach served as co-creation method. ${ }^{24}$

Around 20 NICU healthcare professionals participated in 'co-creation sessions'. A co-creation session included two to five NICU healthcare professionals and one to three students, and served to demonstrate and discuss design proposals, mock-ups and prototypes; for example, simulating feedback scenarios (the sensory and cognitive ergonomic aspects of visual feedback that would optimise hand hygiene compliance) with sketches attached to a real incubator and computer visualisations (figure 1). The co-creation sessions lasted $30 \mathrm{~min}$ and resembled an informal, unstructured, interactive group interview. Alternative design proposals could be assessed, after which discussions between NICU healthcare professionals, students and teacher-researchers led to design decisions. Mostly, two consecutive co-creation sessions took place for one specific design decision, and in most cases, this led to a congruous opinion. All sessions were documented by taking notes, photos and or videos.

Inclusion to the co-creation sessions was limited to NICU nurses and housekeeping staff, all being NICU staff at the Erasmus MC-Sophia Children's Hospital in Rotterdam. No parents of preterm infants were involved because they do not (need to) disinfect their hands with ABHR. In addition to the co-creation sessions, we conducted semistructured interviews with NIDCAP-certified specialists.

In total, 32 third-year and fourth-year students of different bachelor degree educational programmes (Physician Assistant, Occupational Therapy, Industrial Design Engineering, Healthcare Technology, Electrical Engineering, Technical Software Engineering) did the design research, usually in teamwork, in increments with constant participation of the NICU staff.

\section{Feedback scenario 'Protocol Correct'}

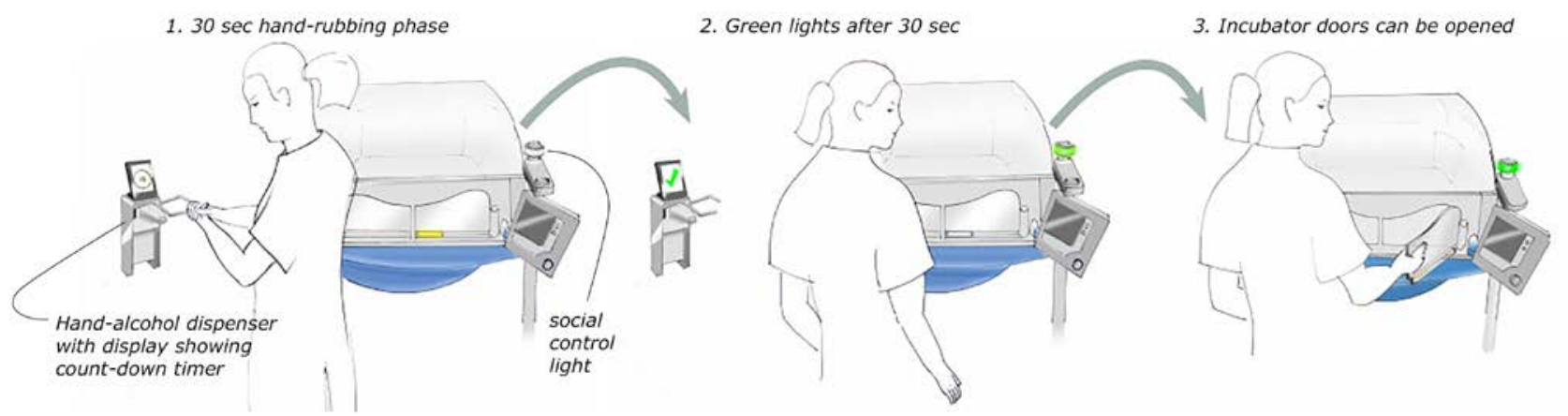

Figure 1 Visualisation of a feedback-scenario (increment 3, 2014). 
Table 1 Increments in the design research process

\begin{tabular}{|c|c|}
\hline Increment \# (year) & Results, decisions, prototypes \\
\hline $\begin{array}{l}\text { Increment } 1 \text { (2011) } \\
\text { Preliminary study }\end{array}$ & $\begin{array}{l}\text { Theoretical design for electronics and programme structure diagram was developed that provides feedback by use of two } \\
\text { and, respectively, three LEDs, including two micro-switch sensors. } \\
\text { The system only gives feedback about using the dispenser (yes or no) before opening the incubator door; no feedback was } \\
\text { provided about the necessary } 30 \text { s interval between dispensing alcohol and opening the incubator door. The system was } \\
\text { analogue so could neither record nor save any data. }\end{array}$ \\
\hline $\begin{array}{l}\text { Increment } 2 \text { (2013) } \\
\text { Research into feedback scenarios }\end{array}$ & $\begin{array}{l}\text { Red light as feedback should be avoided because it can be confused with other red safety alarm lights. A constant orange- } \\
\text { coloured to yellow-coloured light was preferred for the stand-by modus (the 'idle' state of the feedback system before } \\
\text { dispending alcohol). Alternating orange to yellow light was preferred for 'negative' feedback, and green light for positive } \\
\text { feedback. } \\
\text { Sound as feedback was rejected to prevent discomfort for prematurely born infants and confusion with vital signs monitors. } \\
\text { NICU healthcare professionals desired a visual timer that shows the } 30 \text { s countdown near the incubator doors for example, a } \\
\text { strip of } 10 \text { LEDs, of which one would dim in each } 3 \mathrm{~s} \text { time frame. } \\
\text { The idea rose to have a display above the alcohol dispenser showing a welcome screen, to remind the healthcare } \\
\text { professional to disinfect the hands, and a } 30 \text { s countdown timer during hand rubbing. } \\
\text { The feedback scenario was translated in a programme structure diagram and a proof-of-principle prototype was realised } \\
\text { based on an Arduino microprocessor, a LED strip with 3D printed housing, a micro-switch in the alcohol dispenser and a } \\
\text { magnetic switch (reed) on the incubator door. }\end{array}$ \\
\hline
\end{tabular}

Increment 3 (2014)

Validation of feedback scenario

Increment 4 (2015)

Further research into the physical ergonomics, addition of Wi-Fi and database

\section{Increment 5 (2016)}

Final design of electronics, software and housing, including Wi-Fi, data server and dashboard

- NICU healthcare professionals requested a 'social control light' above each incubator visible for all NICU healthcare professionals and parents present. This was to make compliance with hand hygiene 'visible' and was added to the feedback scenario.

Furthermore, NICU healthcare professionals desired an additional video being played showing (during the $30 \mathrm{~s}$ ) instructions for correct hand rubbing technique.

Electronics and plastic housing parts for the LED strip and the social control light (including connecting wires situated on the incubator) were designed and evaluated with NICU healthcare professionals.

- A second proof-of-principle prototype was built based on Arduino, a RGB LED strip and RGB LED social control light with 3D printed plastics housing parts.

- The prototype was complemented with a 7-inch display showing a sequence of still pictures with hand rubbing instructions, suggesting a moving video. The video also included a 'ring' of green rectangles forming in $30 \mathrm{~s}$, as a countdown timer.

- A Wi-Fi module was added that can wirelessly send recorded compliance data to a computer, registering when alcohol was dispensed and the elapsed time between dispensing and opening the incubator door. The compliance data of multiple incubators were visualised in one view in a dashboard.

- To demonstrate the complete feedback system to NICU healthcare professionals, a fully working prototype was mounted on a Dräger Caleo incubator (Dräger, Lübeck, Germany, type Caleo).

- The manual alcohol dispenser (lever operated) was replaced by a touchless operated dispenser (Ophardt, Issum, Germany, type Ingo-man plus Touchless) that eliminates touching the handle with a hand, which is regarded more safe hygienically.

- Ergonomic placement of the main unit and display on the incubator was re-evaluated and the unit was replaced from the left side (where it blocked view on monitors) to the right side of the incubator.

The final architecture of software and electronics was developed according to the method of structured analysis of Yourdon. $^{32}$

The final design and construction of the plastic housing parts was engineered for 3D print production based on the physical dimensions of printed circuit boards, the touchless dispenser, the display and available space around the standard $38 \mathrm{~mm}$ tube of the incubator.

- The LED-strip housing was re-designed and could now be clicked on the incubator door (instead of attaching it with doublesided tape, which was un-desirable due to cleaning requirements).

- Database server software was developed including a new dashboard.

The final design and construction of the plastic housing parts and electronics were evaluated with and approved by infection prevention specialists and medical device safety specialists.

LED, light-emitting diode; NICU, neonatal intensive care unit; RGB, red green blue.

Table 1 describes the five increments in the development of an incubator hand hygiene feedback system, which we named the Incubator Traffic Light. In the first co-creation sessions (increment 2, 2013), ethical aspects (eg, feelings regarding privacy and integrity) were discussed. It appeared that most NICU healthcare professionals would support a feedback system as long as no data directly related to patients or NICU healthcare professionals would be logged. From the first interviews with professionals, it appeared that they would like to have some form of visual feedback for the prescribed 30 s drying time near the incubator doors. This was provided for by incorporating coloured light-emitting diodes (LEDs). In addition, the hand alcohol dispenser needed to be placed as close as possible to the incubator doors. The manually lever operated ABHR dispenser that was in use at the time could not be placed directly on the incubator, however, as the noise and vibrations could disturb the baby. The later introduced touchless operated dispenser that was noiseless, and healthcare professionals saw no problem in placing this dispenser directly on the incubator.

\section{RESULTS}

The final prototype of the Incubator Traffic Light provides visual feedback by a display situated above a touchless ABHR dispenser, a LED strip situated on one of the doors and a social control light situated on an aerial above the display (figure 2). 


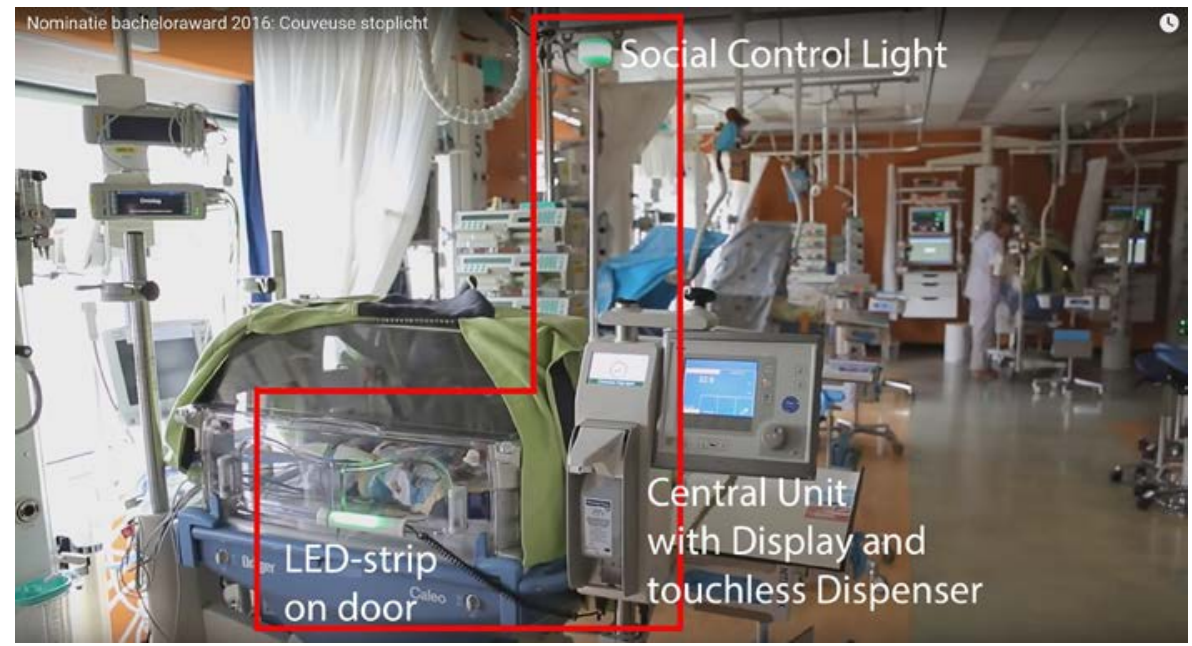

Figure 2 Final prototype of the incubator traffic light, located on the neonatal intensive care unit, https://youtu.be/NsNfHdSaTLo (increment 5, 2016). LED, light-emitting diode.

Feedback on hand hygiene compliance is provided via four modes: (1) stand-by; (2) hand rubbing; (3) protocol correct and (4) protocol incorrect (figure 3). The stand-by mode serves as the 'red traffic light' (although with amber colour, to avoid unnecessary red light). 'Hand rubbing' starts by placing a hand under the dispenser's tap point to activate the touchless dispenser. In the hand rubbing mode, the blue light on the LED strip and the blue social control light indicate that the hand rubbing is going on. In addition, the display shows a video with hand rubbing instructions (showing a good execution of hand rubbing with $\mathrm{ABHR}$ ) and a graphic $30 \mathrm{~s}$ countdown timer. After $30 \mathrm{~s}$, the next mode displayed is either the 'protocol

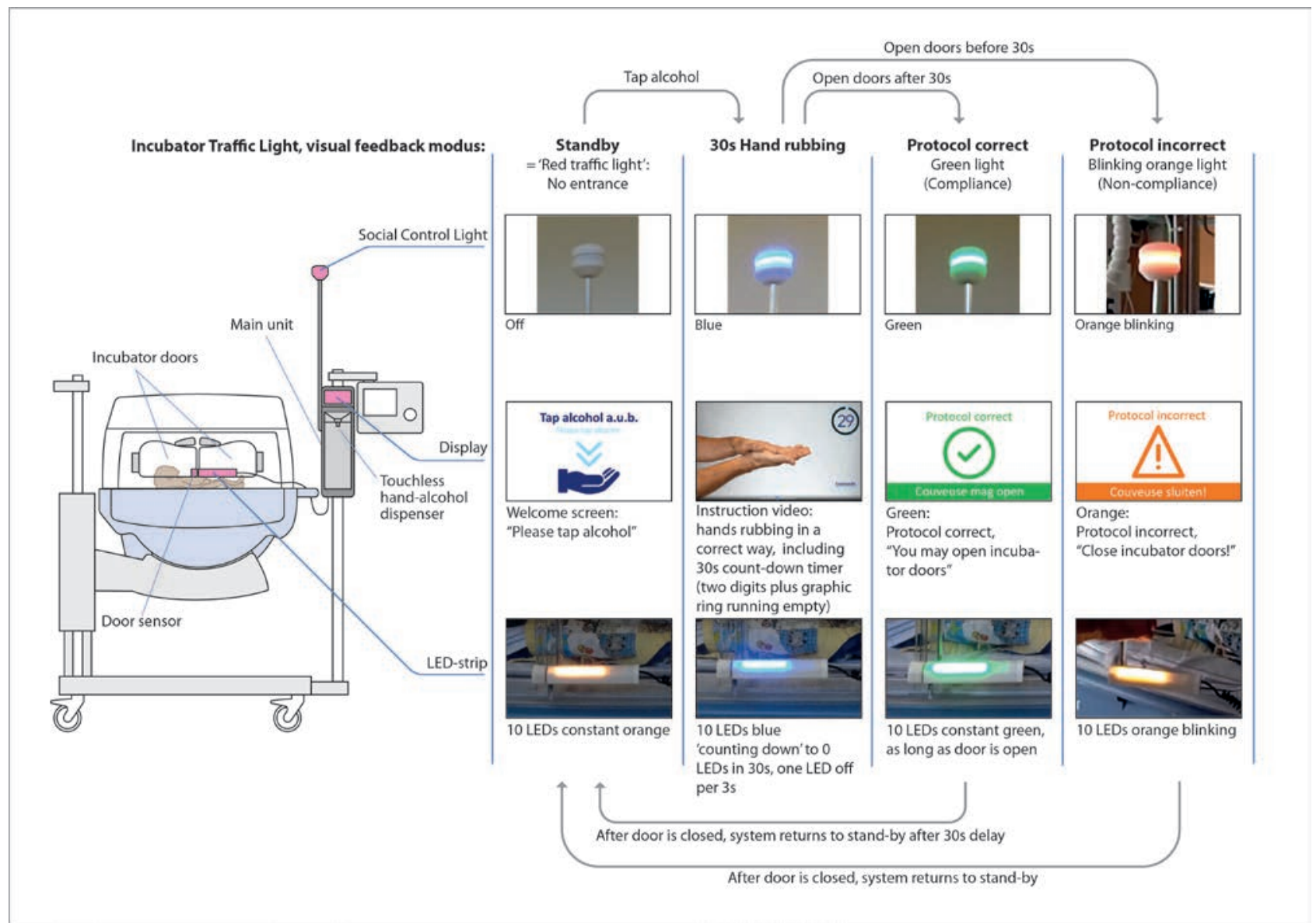

Figure 3 Visual feedback per modus and elements of the incubator traffic light. LED, light-emitting diode. 


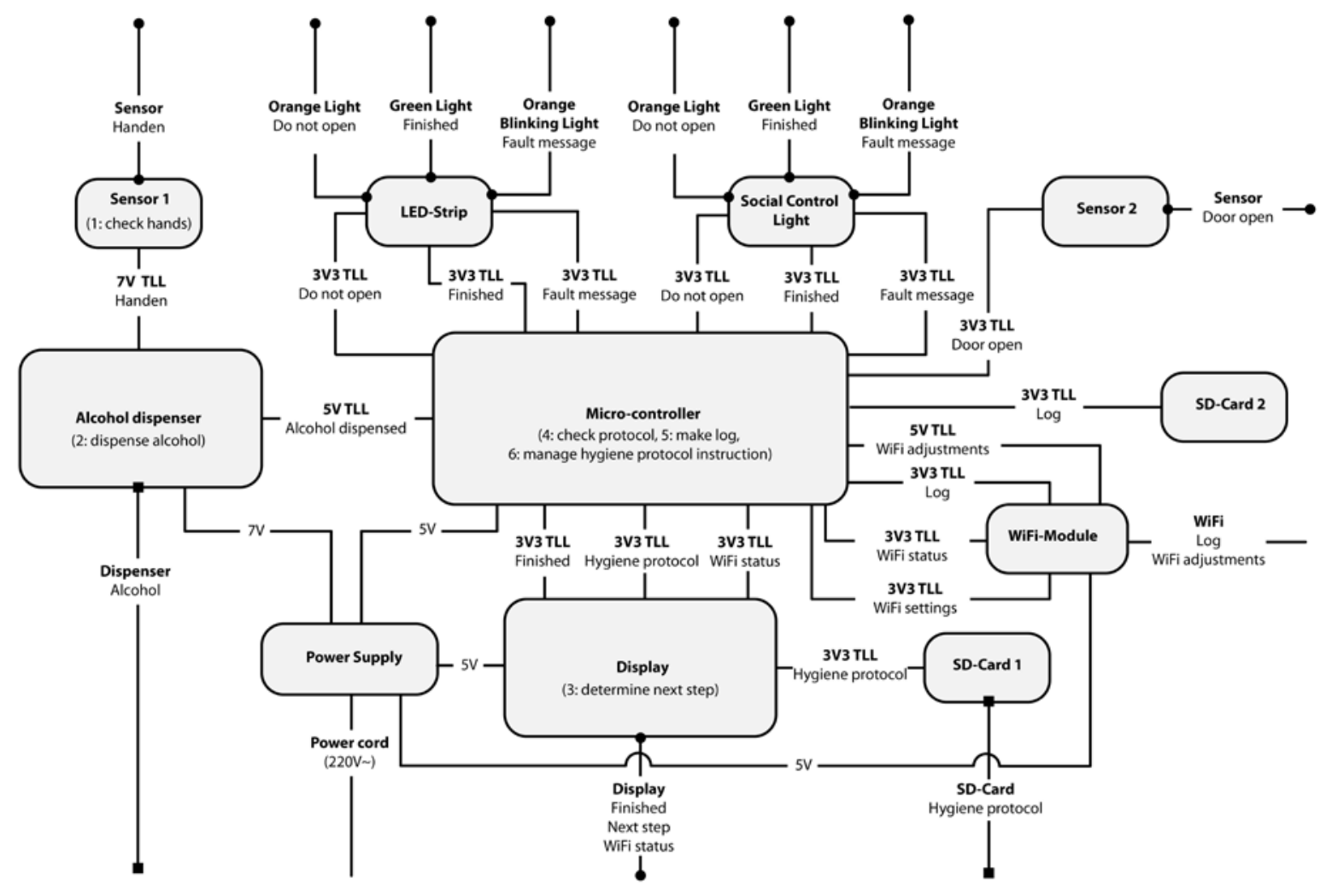

Figure 4 Interconnect diagram of the electronics of the incubator traffic light (increment 5, 2016).

correct' ('green light') or the 'protocol incorrect' ('orange blinking light'); the latter is the case if the door is opened before $30 \mathrm{~s}$ have elapsed, or alcohol has not been dispensed.

\section{Hardware}

The system's hardware consists of a main unit of two plastic housing parts (3D printed $\mathrm{ABS}$ ) that contain a touchless hand alcohol dispenser (Ophardt, Issum, Germany, type: Ingo-man plus Touchless), a 4.3inch colour display (Graphic LCD TFT RGB display $480 \times 272$ pixels, 4D systems, Minchinbury, Australia, type: uLCD-43D) and a central processing module (Atmel, San Jose, USA, type: ARM processor 32-bit ATSAM4SD32CA-AU) that runs on custom developed software and is powered by a custom designed power module (figure 4).

The front plastic housing part integrates and connects all modules and can be mounted to the $38 \mathrm{~mm}$ steel tube of the incubator (Dräger, Lübeck, Germany, Type: Caleo). The backside housing part is mounted to the front part as a protective and aesthetic cover. Via an Euronorm C13-net connector the system is connected to one of the internal 230V Euronorm C-13 net output of the incubator, and is thereby independent from an external $230 \mathrm{~V}$ net connection. To comply with the electro-technical requirements for devices used in a clinical setting, the metal housing of the dispenser and the aluminium aerial rod, that holds the social control light, are electrical grounded. The aerial rod that sticks out from the main unit contains the social control light at its end (approximately $1.8 \mathrm{~m}$ from the ground). This control light consists of a round array of RGB (red blue green) LEDs in a 3D printed plastic housing. The LED strip that is click-mounted to the ridge of the door contains a printed circuit board with an array of 10 RGB Surface Mounted Device LEDs plus a reed switch (electrical switch operated by a magnetic field) that is activated by a magnet on the opposite door functioning as a door sensor.

\section{Software}

The database server software is installed on a cloud server and collects the compliance and non-compliance data per incubator via Wi-Fi. The data are visually represented on a computer dashboard (figure 5). The current design of the dashboard displays (a) the 'last connect time'; (b) the incubator 'statistics over last month': the total number of sequences (A sequence is understood to be an logged data record: the time between dispensing alcohol and opening the doors); (c) the 'duration of sequences' in a time graph and (d) the 'state of sequences' in a block diagram, representing the correct and faulty sequences. 


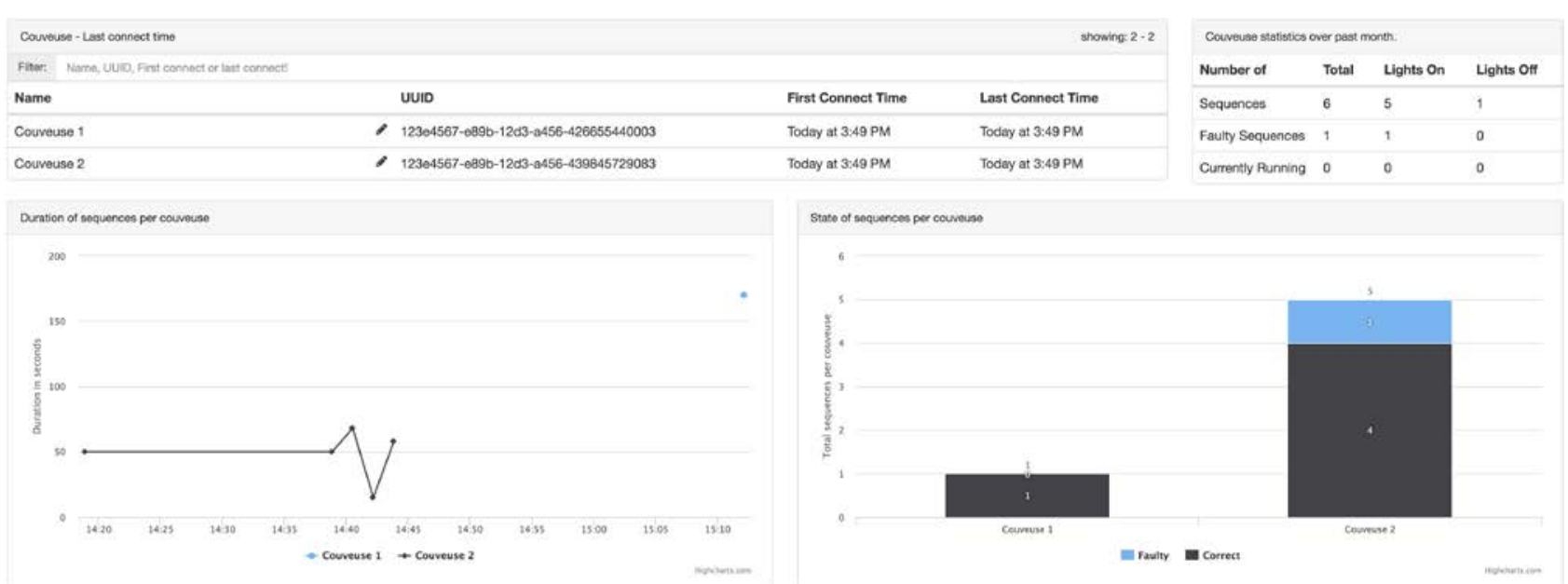

Figure 5 Dashboard visualising the data of compliance or non-compliance per incubator (increment 5, 2016).

The data records consist only of time statistics and no patient or clinicians details.

The hardware and software can be configured in two configurations with the use of a jumper switch on the central processing module: 'lights on' or 'lights off'. These two configurations are necessary for our future effect study in which we will compare hand hygiene compliance in one NICU room with 10 fully functional Incubator Traffic Light systems ('lights on') with that in another room with 10 systems without visual feedback ('lights off').

\section{DISCUSSION}

The aim of this project was to design a hand hygiene feedback system for neonatal incubators that provide visual feedback in line with the hand hygiene protocol: $30 \mathrm{~s}$ hand rubbing with ABHR before touching the baby in the incubator. The system also had to collect compliance data. The result is a fully functional prototype, the Incubator Traffic Light system, which fits on the Dräger Caleo incubator.

As mentioned in the Introduction section, we applied the European EN 1500 guideline as well as the ABHR manufacturer's guideline that prescribes 30 s rubbing and dry time. Other guidelines such as the WHO guideline for hand hygiene in healthcare ${ }^{25}$ do not recommend a specific rubbing time ('rub until hands are dry'). A study comparing the effectiveness of ABHR for different rubbing times concluded that the effectiveness with a $30 \mathrm{~s}$ rubbing time is not significantly better that that with a $15 \mathrm{~s}$ rubbing time. ${ }^{26} \mathrm{In}$ case future studies prove that ABHR time could be reduced, the Incubator Traffic Light system can be easily adapted.

A hand hygiene education programme and sequential promotion initiatives have served as behaviour change interventions to improve hand hygiene compliance in a NICU setting. ${ }^{3} 27-29$ The education programme was associated with positive effects on hand hygiene compliance, although a 'wash out' effect was observed during 6-month follow-up. ${ }^{3}$ An intervention in which screensavers were displayed with visual reminders had a positive effect on hand hygiene compliance; it is unknown, however, whether the effect is sustained on the long term. ${ }^{28}$ An interrupted time study over 10 years concluded that the positive effect of sequential hand hygiene promotion interventions (education programme, gain-framed screen saver messages and an infection prevention week with an introduction on consistent glove use) on the infection incidence at a NICU 'might be sustainable'.

We could not find information on technical interventions like ours aimed at behaviour change regarding hand hygiene compliance in the NICU setting in the literature, patent databases or non-scientific databases. In previous hand hygiene compliance studies that used closed-loop visual feedback, ${ }^{20-22}$ the feedback loop also starts at the moment the ABHR is dispensed from a alcohol dispenser, gives feedback before patient contact and sends compliance data to a centralised database. Our system, however, was designed in the context of contact with a baby in an incubator, with the feedback focused on compliance with the required (30s) rubbing time. Other systems only give feedback about whether or not ABHR is dispensed (dispenser activation) and or skin contact with alcohol is achieved (alcohol sensor) before a patient is approached. Furthermore, other systems require some form of (personal) identification to start the feedback loop (eg, a badge or sensor carried on the person) and feedback is directly linked to or visual on that person. ${ }^{22} 31$ Our system is anonymous and starts when the dispenser is activated. Personal data are not recorded; anonymity was a strict requirement that emerged during the participatory design sessions.

\section{Strengths}

Letting the end-users serve as co-designers helps accelerate the design process because early design mistakes are avoided and acceptance of a new intervention can 
grow. In this way, we could develop a prototype that was approved by all stakeholders and is ready for clinical safety testing.

Our Incubator Traffic Light not only serves as a hand hygiene reminder, but also stimulates compliance to the recommended rubbing and dry time and, by showing video instructions, good rubbing execution.

The system was developed to be used with a neonatal incubator, but it can also function as a stand-alone hand hygiene feedback unit (without the door sensor and slightly altered feedback settings) everywhere in a hospital.

\section{Limitations}

Achieving sustainable change in behaviour and acceptance of such a system is a delicate matter. In the co-creation sessions, opinions differed about the 'usefulness' of such intervention. It appeared necessary to constantly re-evaluate design decisions. Not all design decisions can be backed with logged evidence because not all discussions with NICU healthcare professionals were recorded in writing. For example, faulty conclusions were drawn with regard to the ergonomic placement of the main unit and display on the incubator because the sessions had not been conducted in the actual NICU setting. In a co-creation session in the incubator storage room, it became evident that the main unit and display needed to be placed on the left side of the incubator (seen from the 'working side' of the incubator, with the head of the baby to the left). After re-evaluation with prototypes in the real NICU situation, however, it became clear that the right side was far more logical from a usability point of view considering space and workflow.

\section{Future studies}

The data server software, specifically the design of the dashboard's graphic user interface (figure 5), is not yet optimally user-friendly and has to be re-designed in co-design with direct end-users.

An observational study with a control group is planned to validate the effect of our system on compliance with hand hygiene as primary outcome and the incidence of infants' bloodstream infections as a secondary outcome. To this aim, three identical NICU units with each 10 incubator-bed places will be randomly divided into a unit with 10 active Incubator Traffic Light systems (intervention unit, 'lights on'), a unit with 10 non-active systems (non-intervention unit, 'lights off', but with compliance registration) and a unit with no systems (control-unit, compliance registration by visual observation). The study consists of three phases: pre-assessment, intervention and follow-up.

\section{CONCLUSION}

We developed a sophisticated technical intervention to support appropriate hand hygiene at NICUs. The planned observational study should prove that the 'Incubator Traffic Light' system contributes to sustainable improvement of hand hygiene compliance near neonatal incubators.

\section{Author affiliations}

${ }^{1}$ Institute of Engineering \& Applied Science, Rotterdam University of Applied Sciences, Rotterdam, the Netherlands

${ }^{2}$ Research Centre Innovations in Care, Rotterdam University of Applied Sciences, Rotterdam, the Netherlands

${ }^{3}$ Department of Pediatrics, Division of Neonatology, Erasmus MC Sophia, Rotterdam, the Netherlands

${ }^{4}$ Create4Care, Erasmus MC, Rotterdam, the Netherlands

${ }^{5}$ Department of BioMechanical Engineering, Faculty of Mechanical, Maritime and Materials Engineering, Delft University of Technology, Delft, the Netherlands

Acknowledgements We thank all NICU healthcare professionals of Erasmus University Medical Center-Sophia Children's Hospital and all the students and their guiding teachers of the Rotterdam University of Applied Sciences who contributed to the development of the Incubator Traffic Light. We also thank Ko Hagoort for text editing.

Contributors $\mathrm{RHJvG}$ and $\mathrm{OKH}$ were involved in the planning and execution of the study and writing the associated manuscript, including revision. LSGLW was involved in writing and revising the manuscript. All authors read and approved the final manuscript.

Funding The authors have not declared a specific grant for this research from any funding agency in the public, commercial or not-for-profit sectors.

Competing interests None declared.

Patient consent for publication Not required.

Provenance and peer review Not commissioned; externally peer reviewed.

Data availability statement Data are available upon reasonable request.

Open access This is an open access article distributed in accordance with the Creative Commons Attribution Non Commercial (CC BYNC 4.0) license, which permits others to distribute, remix, adapt, build upon this work non-commercially, and license their derivative works on different terms, provided the original work is properly cited, appropriate credit is given, any changes made indicated, and the use is non-commercial. See: http://creativecommons.org/ licenses/by-nc/4.0/.

\section{ORCID iD}

Ronald H J van Gils http://orcid.org/0000-0003-2994-3435

\section{REFERENCES}

1. Beck S, Wojdyla D, Say L, et al. The worldwide incidence of preterm birth: a systematic review of maternal mortality and morbidity. Bull World Health Organ 2010;88:31-8.

2 Ista E, van der Hoven B, Kornelisse RF, et al. Effectiveness of insertion and maintenance bundles to prevent central-lineassociated bloodstream infections in critically ill patients of all ages: a systematic review and meta-analysis. Lancet Infect Dis 2016;16:724-34.

3. Helder OK, Brug J, Looman CWN, et al. The impact of an education program on hand hygiene compliance and nosocomial infection incidence in an urban neonatal intensive care unit: an intervention study with before and after comparison. Int J Nurs Stud 2010;47:1245-52.

4. Adams-Chapman I, Bann CM, Das A, et al. Neurodevelopmental outcome of extremely low birth weight infants with Candida infection. J Pediatr 2013;163:961-7. 
5. Verhagen AAE, Dorscheidt JHHM, Engels B, et al. End-Of-Life decisions in Dutch neonatal intensive care units. Arch Pediatr Adolesc Med 2009;163:895-901.

6. Stoll BJ, Hansen NI, Adams-Chapman I, et al. Neurodevelopmental and growth impairment among extremely low-birth-weight infants with neonatal infection. JAMA 2004;292:2357-65.

7. Aziz K, McMillan DD, Andrews W, et al. Variations in rates of nosocomial infection among Canadian neonatal intensive care units may be practice-related. BMC Pediatr 2005;5:1-12.

8. Donovan EF, Sparling K, Lake MR, et al. "The investment case for preventing NICU-associated infections,". Am J Perinatol 2013;30:179-84.

9. Levy SB, Marshall B. Antibacterial resistance worldwide: causes, challenges and responses. Nat Med 2004;10(12 Suppl):S122-9.

10. Sax H, Allegranzi B, Chraïti M-N, et al. The world Health organization hand hygiene observation method. Am J Infect Control 2009;37:827-34.

11. Pharande P, Lindrea KB, Smyth J, et al. Trends in lateonset sepsis in a neonatal intensive care unit following implementation of infection control bundle: a 15-year audit. $J$ Paediatr Child Health 2018;54:1314-20.

12. Janota J, Šebková S, Višňovská M, et al. Hand hygiene with alcohol hand rub and gloves reduces the incidence of late onset sepsis in preterm neonates. Acta Paediatr 2014;103:1053-6.

13 European Standard for Hygienic Hand Disinfection EN 1500:2013. Chemical disinfectants and antiseptics - Hygienic handrub-Test method and requirements (phase 2/step 2), CEN DIN en 1500:2013-07, 2013.

14. Tyagi M, Hanson C, Schellenberg J, et al. Hand hygiene in hospitals: an observational study in hospitals from two southern states of India. BMC Public Health 2018;18:1299.

15. Erasmus V, Daha TJ, Brug H, et al. Systematic review of studies on compliance with hand hygiene guidelines in hospital care. Infect Control Hosp Epidemiol 2010;31:28394.

16. WHO. The World Health Organization Guidelines on Hand Hygiene in Health Care, in Hand hygiene practices among health-care workers and adherence to recommendations. Switzerland: The World Health Organization, 2009: 66-77.

17. Marra AR, Edmond MB. New technologies to monitor healthcare worker hand hygiene. Clin Microbiol Infect 2014;20:29-33.

18. Ward MA, Schweizer ML, Polgreen PM, et al. Automated and electronically assisted hand hygiene monitoring systems: a systematic review. Am J Infect Control 2014;42:472-8.
19 Ellison RT, Barysauskas CM, Rundensteiner EA, et al. A prospective controlled trial of an electronic hand hygiene reminder system. Open Forum Infect Dis 2015;2.

20. Storey SJ, FitzGerald G, Moore G, et al. Effect of a contact monitoring system with immediate visual feedback on hand hygiene compliance. J Hosp Infect 2014;88:84-8.

21. Marra AR, Sampaio Camargo TZ, Magnus TP, et al. The use of real-time feedback via wireless technology to improve hand hygiene compliance. Am J Infect Control 2014;42:608-11.

22. Michael H, Einloth C, Fatica C, et al. Durable improvement in hand hygiene compliance following implementation of an automated observation system with visual feedback. Am J Infect Control 2017;45:311-3.

23. Moody C, Callahan TJ, Aldrich H, et al. Early initiation of newborn individualized developmental care and assessment program (NIDCAP) reduces length of stay: a quality improvement project. J Pediatr Nurs 2017;32:59-63.

24. Wauben LSGL, Doorn CMDV, Klein J, et al. Participatory design: implementation of time out and Debriefing in the operating theatre. JDR 2011;9:220-40.

25. Pittet D, Allegranzi B, Boyce J, et al. The world Health organization guidelines on hand hygiene in health care and their consensus recommendations. Infect Control Hosp Epidemiol 2009;30:611-22.

26. Pires D, Soule H, Bellissimo-Rodrigues F, et al. Hand hygiene with alcohol-based hand rub: how long is long enough? Infect Control Hosp Epidemiol 2017;38:547-52.

27. Helder OK, Latour JM. Undergraduate nurse students' education in infection prevention: is it effective to change the attitude and compliance with hand hygiene? Nurs Crit Care 2010;15:39-40.

28. Helder OK, Weggelaar AM, Waarsenburg DCJ, et al. Computer screen saver hand hygiene information curbs a negative trend in hand hygiene behavior. Am J Infect Control 2012;40:951-4.

29. Weggelaar-Jansen AM, van Buren-Jansen E, van 't Schip S, et al. Design study to develop screen savers aimed at improving hand hygiene behavior. Am J Infect Control 2016;44:860-7.

30. Helder OK, Brug J, van Goudoever JB, et al. Sequential hand hygiene promotion contributes to a reduced nosocomial bloodstream infection rate among very low-birth weight infants: an interrupted time series over a 10 -year period. Am J Infect Control 2014;42:718-22.

31. Conway LJ. Challenges in implementing electronic hand hygiene monitoring systems. Am J Infect Control 2016;44(5 Suppl):e7-12.

32. Yourdon E. Modern structured analysis, 1989. 